(C) 2021, The Authors. Published by Elsevier Inc. and Fass Inc. on behalf of the American Dairy Science Association ${ }^{\circledR}$. This is an open access article under the CC BY-NC-ND license (http://creativecommons.org/licenses/by-nc-nd/4.0/).

\title{
Views of American animal and dairy science students on the future of dairy farms and public expectations for dairy cattle care: A focus group study
}

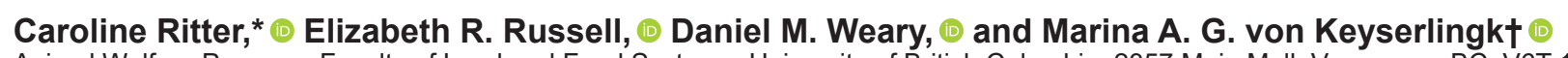

Animal Welfare Program, Faculty of Land and Food Systems, University of British Columbia, 2357 Main Mall, Vancouver, BC, V6T 1 Z6 Canada

\begin{abstract}
Students completing advanced degrees in dairy or animal science may go on to have a major impact on the food animal agriculture industries. The aim of this study was to better understand student views of the future of dairying, including changes in practices affecting animal care on farms as well as perceived public perceptions. We conducted 6 focus group sessions with undergraduate students enrolled in the 2019 US Dairy Education and Training Consortium held in Clovis, New Mexico, and used explorative key word analysis of written notes and thematic analysis of the semi-structured discussions. Some "must-haves" of future animal care on dairy farms included increased use of technology, group housing of calves, and adequate facilities, including enrichment. Students also discussed their views of public expectations regarding animal care on dairy farms, and measures that they felt must be put into place to address these expectations in the coming years. Although the influence of the public was highlighted by the students, they were not always certain what specific values the public holds and doubted the feasibility and practicality of some expectations, such as providing pasture access or keeping the calf and cow together. They further demonstrated uncertainty about how best to align the directions of the industry with public expectations. Although they felt that public education could be used to demonstrate the legitimacy of dairy practices, they also believed that the industry should strive to find compromises and work toward meeting public expectations. Deciding what animal welfare considerations (e.g., naturalness, affective states, or animal health) were most relevant was a challenge for the students, perhaps reflecting diverging messages received during their own education.
\end{abstract}

Received October 2, 2020

Accepted March 1, 2021.

*Current affiliation: Department of Health Management, Atlantic Veterinary College, University of Prince Edward Island, 550 University Ave., Charlottetown, PE, C1A 4P3 Canada.

†Corresponding author: marina.vonkeyserlingk@ubc.ca
Key words: agricultural education, social license, animal welfare, public attitudes, citizen values

\section{INTRODUCTION}

In recent years public interest in the care of farmed animals (Clark et al., 2016) and the naturalness of food products (Román et al., 2017) has been growing. Compared with other livestock industries, the dairy industry has received less attention and has a more positive public image (Schröder and McEachern, 2004; Boogaard et al., 2011). Nonetheless, to maintain public trust, agricultural industries - including the dairy sector-must conform to widely held public values, including those around animal care (reviewed by Alonso et al., 2020). For the purposes of this discussion, the public is defined as people who have no involvement in the dairy industry, who are often unaware of the specific practices associated with dairy farming (Cambridge Business Dictionary, 2011; Ventura et al., 2016a). Because their potential to influence the demand for specific food products (Isenhour, 2011), public views, concerns, and preferences should be taken into consideration (Bennett et al., 2002). However, stakeholders within the livestock industries often disagree with the views of members of the public in their evaluation of the importance of welfare issues. For example, stakeholders working within the livestock industries seem to ascribe a higher importance to the biological functioning of the animals (e.g., health, production, and fertility) and are less concerned than members of the public about the animals' ability to perform natural behaviors (Te Velde et al., 2002; Verbeke, 2009; Cardoso et al., 2019). Furthermore, people working within the agricultural industry may have difficulties in accepting public views as valid and instead consider these objections a reflection of public ignorance about modern farming methods (de Rooij et al., 2010; Benard and de Cock Buning, 2013; Ventura et al., 2016b), suggesting a disconnect between the importance of accounting for interests of members of the public and the ability of industry stakeholders to do so. To help bridge this gap, future generations of agricultural professionals could be better trained to consider a 
diversity of viewpoints; as Howlett et al. (2016) argued, education must foster critical and creative thinking to address the complex relationship between social, economic, and environmental factors.

Future advisors of the dairy industry include agriculture extension agents, agronomists, and nutrition consultants, all positions that are open to students pursuing an undergraduate degree in agriculture. Given the important role that undergraduate training plays in preparing students for future employment in the farm animal industries, it is surprising that most of the available literature assessing attitudes toward animal welfare in the educational context has focused on veterinary students (e.g., reviewed by Cornish et al., 2016). There appears to have been little focus on understanding the views of undergraduate animal and dairy science students.

Thus, the aim of this study was to assess undergraduate students' views of the future of dairy farming, especially animal care, and explore how they regard the role of the public in influencing this future. A better understanding of student views may inform new curricula to help students become critical thinkers and leaders in their field.

\section{MATERIALS AND METHODS}

\section{Research Approach}

A qualitative research approach was chosen because of its ability to obtain detailed descriptions and gain an in-depth understanding of individuals' opinions, feelings, and experiences (Denzin and Lincoln, 1994). Furthermore, focus groups are suitable to explore a variety of different views and stimulating discussions among participants (Krueger and Casey, 2009). This study was approved by the ethics board of The University of British Columbia (H18-02880).

\section{Participating Students}

Six focus groups, each with a convenience sample of 7 to 8 students ( 45 students total), were conducted immediately before the first session of the US Dairy Education \& Training Consortium (USDETC) held in Clovis, New Mexico, on May 14, 2019. All students enrolled in the 2019 consortium were given the opportunity to participate but were also clearly told that this was voluntary and that any student wishing not to participate could remain in the coffee room; all students consented to participate. The USDETC is a 6 -wk dairy training program that includes theoretical classroom instruction combined with a field trip where the learning outcomes during the classroom session are discussed using real-life scenarios (see https:// usdetc.tamu.edu/ for a description of the consortium aims and a full list of participating universities). Approximately $50 \%$ of the students participating in the 2019 6-wk course were enrolled in animal and dairy science programs of universities located in the South and Southwest, with the remaining coming from similar programs taught in universities spread across the rest of the United States. This annual event attracts students interested in dairy science, who are currently registered in their third or fourth year of their undergraduate degree. The consortium program was first established in 2008 to meet the educational and training needs of the rapidly expanding dairy industry in the United States and is funded through a partnership between academia, allied industries, and dairy producer organizations (see https://usdetc.tamu.edu/).

\section{Researchers and Facilitators}

A researcher's positionality refers to the relationship between researcher and participants, and between researcher and the subject matter; therefore, a positionality statement allows readers to contextualize the researcher and research (Mason-Bish, 2019). This is important as the researchers' positionality can influence how data are collected and analyzed and how results are interpreted (Cohen and Crabtree, 2008; Corlett and Mavin, 2018). The research team had experience conducting a variety of research activities related to dairy cattle with a strong focus on animal welfare research. The first author's (C.R.) positionality was further influenced by her training in veterinary medicine and she was familiar with current contentious issues in the dairy industry but less aware of the views of US undergraduate dairy students. A critical realist paradigm was adopted for this study, which assumes that social structures and events underly human actions and that individuals' perspectives are influenced by their internal and external contexts (Fletcher, 2017).

Focus groups were facilitated by the coordinators (n $=4)$ and lecturers $(n=2)$ of the consortium, including the last author M.v.K. (professor in Animal Welfare Science), who gave the other facilitators a 30 -min workshop on facilitating focus groups and provided the interview guide before the start of the morning session. Both male and female facilitators were represented. The 6 focus groups were done on the first day of the 6-wk program, immediately following the morning orientation. Participating students were not specifically informed about the background of the authors. Although M.v.K. was scheduled as a lecturer at the consortium, at this 
point, the students had not attended any lectures by her or any of the other lecturers present at the time, and had not engaged in discussion of course material.

\section{Key Words}

At the beginning of the focus groups, each student was provided with several sticky notes and encouraged to individually write down 3 to 5 words or phrases that reflected what they believed are the "must-haves" for the dairy industry in terms of animal care $20 \mathrm{yr}$ from now. This activity encouraged students to think beyond immediate constraints of the industry. Further, generation of key words and phrases ensured that every student had the opportunity to contribute their opinion, to initiate conversations in the following discussion, and documentation of key words and phrases allowed explorative analysis through the generation of a word cloud (Cidell, 2010).

To prepare the written notes for the word cloud, unspecific terms (e.g., "and," "for," "therefore") were deleted. Further, words with the same root and meaning were combined. For example, students used "automation," "automatic," and "automated" to describe the same idea. Words that were mentioned at least 2 times were included in the word cloud that was created using an online software tool (wordclouds.com).

\section{Semi-Structured Discussion}

A semi-structured interview guide that had been developed for a previous study (Ritter et al., 2020) was provided to all facilitators to ensure that discussions covered all aspects relevant to the research. Although the spirit of the questions outlined in the interview guide was adhered to, facilitators had the option to rephrase existing or add probing questions. The interview guide covered the following aspects: (1) What are the "must-haves" of dairy farms in the future, how can they be achieved, and how can they be aligned with public expectations? and (2) What role should policy play to achieve the "must-haves"? For this study, as per the outlined research questions, we focused mainly on the discussion derived from the first part of the interview guide, which included the dynamics as perceived by participating students between the dairy industry and the public.

All focus groups were held simultaneously, and average duration of the discussions was 66 min (range: 59$78 \mathrm{~min}$ ). All sessions were transcribed by a professional transcription service and afterward compared with the audio recordings for accuracy. Then, a qualitative data analysis software (NVivo; QSR International) was used for coding the transcripts. Criteria ensuring the trustworthiness of qualitative data according to Lincoln and Guba (1985) were used to guide the research process. As outlined in the following paragraphs, we used memoing, researcher triangulation, peer debriefing and discussion, a coding framework, and diagramming to provide a description and make sense of theme connections (Nowell et al., 2017).

After familiarization with the data, thematic analysis was used. Codes were applied to identify and label meaningful text passages that were deemed beneficial to answering the research questions (Miles et al., 2014). The first author (C.R.) used a combination of deductive coding based on previously developed codes by Ritter et al. (2020) and open coding by creating inductive codes from the data set (Marshall and Rossman, 2006; Hennink et al., 2011) to complement and adapt deductive a priori codes. An iterative process characterized by continuous refinement resulted in a codebook that grouped codes into overarching themes (DeCuir-Gunby et al., 2011; Roberts et al., 2019).

This codebook was forwarded to another researcher (E.R.) who used it to code the transcripts; any disagreements were discussed, and the codebook changed accordingly. The process was repeated until both researchers believed the codebook accurately represented the data, after which it was further discussed with the last author (M.v.K.). Memoing (Miles et al., 2014) was used throughout data analysis to record reflections about the data and to facilitate organization and interpretation of findings. A thematic map was developed by reviewing the created themes and memos while focusing on connections among codes and themes (Roberts et al., 2019). Similar to the coding process, the researchers discussed the thematic map until agreement was reached.

Unique identifiers were assigned to quotations from participating students (e.g., P4_1) and used to report the results, indicating the focus group (first number) and the student within the group (second number). Further, to shorten a quotation while maintaining its meaning or include explanatory information, square brackets (i.e., [...]) were inserted.

\section{RESULTS}

After reduction of the key words based on relevancy and repetition, 80 unique words that were mentioned 322 times were used in the word cloud (Figure 1). Further, we identified 3 themes from the subsequent semistructured discussion: (1) "must-haves" at the farm level (according to the public), (2) interaction between the public and the dairy industry, and (3) support and joint 


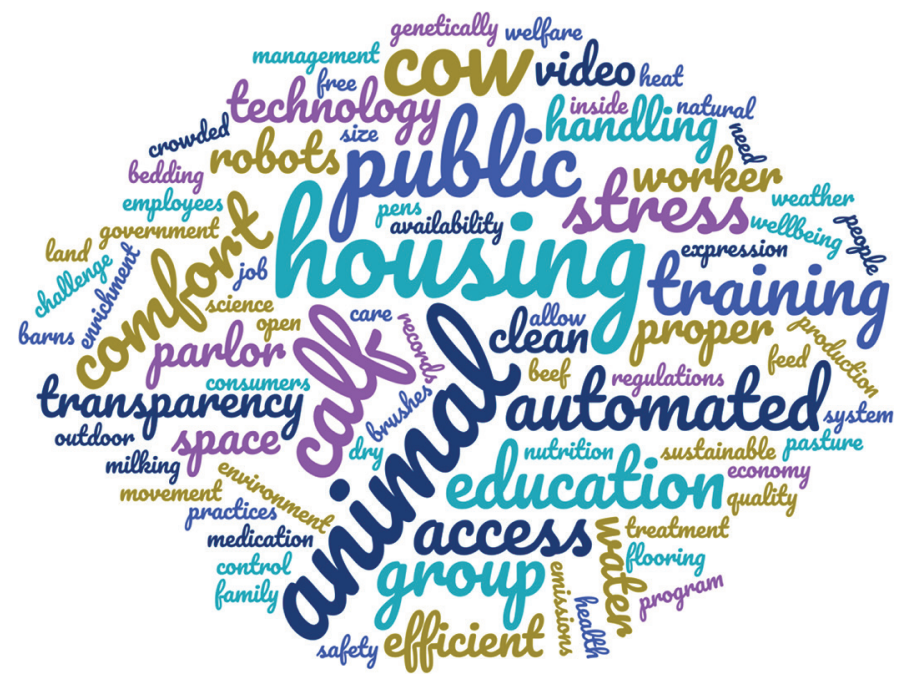

Figure 1. Word cloud of the "must-haves" undergraduate animal and dairy students believed are necessary for dairy farms in $20 \mathrm{yr}$ in terms of animal care.

effort to align the dairy industry with public expectations. These themes including the codes comprising the themes are outlined in the thematic map (Figure 2) and the codebook (Appendix Table A1).

\section{"Must-Haves" at the Farm Level}

Technology and automation of farm processes were major "must-haves" that students highlighted on their written notes and again made reference to during the discussion. One student (P3_5) explained that with the use of technology "we'll be able to really pinpoint when [the cow] is getting sick, if she's starting to stress out, if she's getting hot, stuff like that. And I think that's going to be the biggest thing in welfare." Other students emphasized the consistency of animal care that automation can provide, as explained by P5_1: "With an automated system, you don't have as many welfare issues, because you don't have human aggression and human emotion involved. Which, I think, is also a crucial aspect that those outside the industry need to understand." Students were uncertain how the public would perceive increased automation. Some postulated that the public would want to see increased efficiency in the dairy industry but another student (P3_6) argued: "These animals need human contact, they need love and affection, and they need just that interaction with a person. And whenever it gets to the point where mostly metal and technology is running their lives, I think people are going to have a big issue with it."

When thinking about the human-animal interaction, students agreed that there should be accountability and "zero tolerance" (P6_3) for mishandling cows, includ- ing hitting animals and inappropriate use of electrical prodders. They also highlighted that procedures such as dehorning, hot iron branding, tail docking, and other mutilations are often unnecessary and should be avoided or at least monitored closely. One student (P4_4) referred to ceasing of tail docking when explaining: "So, that really shows the shift in people, and the industry, and consumers caring about animal welfare so much, enough that we would change that." Another student suggested that it would be "a more ethical way of treating animals and managing the industry" (P3_4) if cattle would be bred based on genetic traits that would eliminate certain welfare issues, for example, by breeding cattle that are hornless (polled) or have increased heat tolerance. They further cautioned that the industry should not just push production by selecting specific genetic traits but to "also focus on quality of life for the animal" (P3_3). Students regarded genetic modification of animals as likely in the future, but also believed that the public currently has negative attitudes toward this technology.

Important aspects of facilities that were mentioned related to controlled temperature to avoid heat stress, sufficient air quality, cleanliness, bedding/flooring, and space. Students believed that enrichment such as brushes could be "a good way to increase animal welfare" (P3_3) and "reduce stress" (P3_4). Further, P5_8 explained: "[...] the public would see [enrichment] as a really positive thing, and they would realize that the dairies aren't just jail cells for cows." Similarly, students believed that the "public expects the cow to be in the pasture" (P6_2) but felt that often this may not be feasible (e.g., due to difficulties milking the cows) or desirable (e.g., due to hot weather or muddy grounds). However, they recognized that the dairy industry's image can benefit from finding compromises. For example, one student (P5_6) described the requirement of organic farms to provide pasture access for at least 120 $\mathrm{d}$ and explained: "I think that that's a good example of what the whole industry, conventional as a whole, can look towards doing. [...] saying that this is what we do, and this is our voice, this is our message that we want to give to the public." Similarly, the importance of naturalness of dairy farming to the public was highlighted: "[The] public may demand cows to have more access to grass or expression of what is perceived as natural behaviors" (P1_6), and students stated that some consumers preferred organic products that are more supportive of natural behaviors. However, some students argued that widespread organic production is not feasible: "we just don't have the resources to feed everybody an organic product" (P3_3).

A major discussion point was on calf care. Overall, students felt that group housing of calves was the way 
of the future and would be regarded positively by the public, despite the students' beliefs that grouping would increase the risk of calf disease. One student (P2_2) wondered: "So, what is animal welfare, right? Is animal welfare the sociability aspect, or now you have higher risk of disease in these calves"? and another (P2_1) added: "If you are thinking about welfare, not just health, like yeah. Imagine being locked in a box for the first, however long of your life." Early separation of cows and calves was generally regarded as practical, and it was highlighted that every farm should be consistent in this management practice: "[...] if we have one dairy that's keeping the cows and calves together, then the consumer might expect that from everybody. And that's really not an expectation that we can meet" (P3_3). One student (P1_1) believed leaving calves with the cows "would destroy the dairy industry" and another (P1_4) followed up: "I think a lot of people think that [staying with the calf] is what the cow wants, but that's not necessarily the case."
Students discussed how the dairy industry should consider the environment. As explained by P3_6: "If we just keep focusing on technology, and advances, and genetics, and improving the cows, [...] and forgetting about the environment [...], then eventually it's not going to be able to provide that production anymore and it's going to get rough." Other students commented that especially younger generations "care more and more about the environment" (P1_1) and that there should be more environmental policies because "the consumer wants to see that" (P1_2). Additional topics that were brought up in relation to the environment included the reduction of emissions ["We can work and choose for animals who have $[. .$.$] better feed conversion and really$ less emissions. So, we can work on that, and people will see, '.. they are working on helping the environment"' (P3_6)\}, and improving the ways resources are used \{"We also have to get better use of water. [...] I think if we can make everything a little more efficient and start repurposing things and use more sustainable sources of

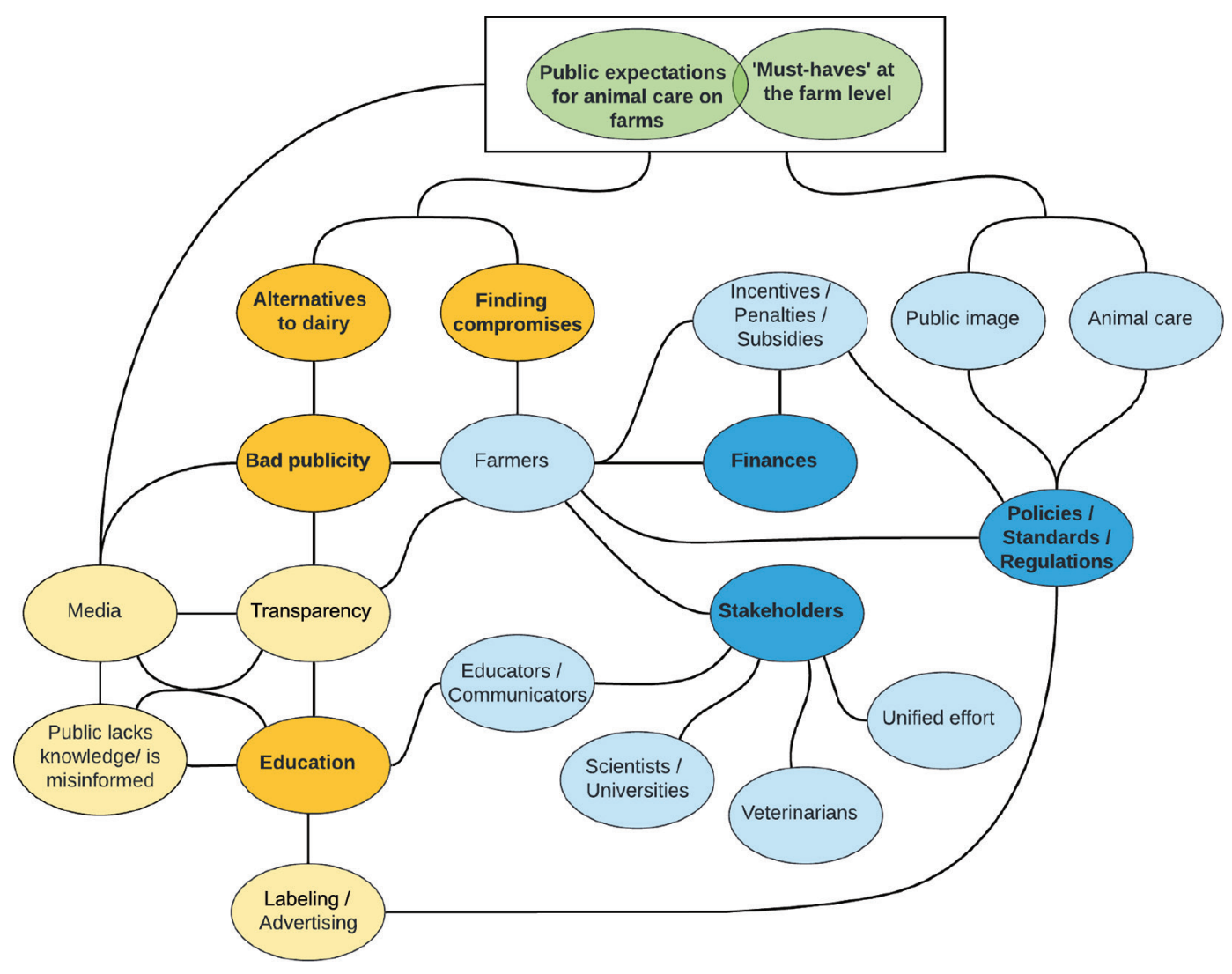

Figure 2. Thematic map generated from focus group transcripts of undergraduate dairy and animal science students. The map highlights students' views of the "must-haves" of animal care on dairy farms in $20 \mathrm{yr}$ and the role of the public in shaping the direction of the dairy industry. Color coding of different themes with darker circles and bold font signifying parent codes: green (no subcodes are displayed) = "must-haves" at the farm level (according to the public); yellow = the interaction of the public or consumer and the dairy industry; blue = support to help align the direction of the dairy industry with public expectations for animal care. 
energy and renewable energy versus nonrenewable, that we might actually have a chance of keeping our world healthy" (P6_5)\}.

\section{Interaction Between the Public and the Dairy Industry}

Students believed that "It's our responsibility, in the near future, to $[. .$.$] have more contact with people. Not$ just focus on production, and only the cattle, and only the farm, but also be aware of the society around us" (P3_4). They realized that "consumers are driving the industry" (P2_5) and that the dairy industry is "going to have to compromise" (P1_4) to meet public expectations. One student suggested, "I think we could learn more about the public to see what we could do, the most effective ways to make a difference" (P2_7). Another stated that industry leaders "need to start talking to our actual producers and be like, 'Okay, so this is what the world wants of us. This is what you want. We're going to have to move towards [the public's] way if you want to keep producing'" (P6_5).

Bad publicity through the media was regarded as a threat because it can lead to negative public perceptions of the dairy industry. One student (P1_1) wondered, "And as an industry, how do we get in front of the bad information?" and P2_2 suggested, "There's a lot of negative [videos] out there, and we just have to make sure we outweigh the negatives by more positives." Other students recognized that the dairy industry was not perfect and that it had to be more open to discussion with lay members of the public: "We're going to have to try and find a way to [provide a complete picture] without being defensive, and show [...] what we have, what we can do to get better" (P6_5). Along the same lines, another student (P2_6) said: "We kind of think we're better than everybody else. [...] If [lay members of the public] say something bad to us, we just kind of throw everything we have at them without thinking about it. [...] We make other people that literally don't know any better, make them feel stupid, and that just pushes everybody back." Hence, students acknowledged the deficiencies of agricultural communication, and believed that this contributed to the lacking in agricultural knowledge among members of the public. Students also stated that it is important for those in the dairy industry to educate "those people on the fence" by trying "to push them towards seeing the truth" (P5_4). The role of agriculture graduates was highlighted by P2_6: "I think we as ag majors need to understand people if we're going to educate them."

Different approaches to reach the public were mentioned and some students suggested educational writing and documentaries. Further, using labels on dairy products to indicate a certain standard of animal care and product quality was regarded as helpful, as were advertisements (on television). However, P3_1 believed that the content shown in the media had to be meaningful to the public ("They don't want to just see slogans with celebrities holding a glass of milk") and P1_5 said that "showing people our science, like why we do this" is the most promising method for improving public understanding of the dairy industry practices. One student provided an example of how the public can be convinced that cow-calf separation is acceptable: "I think that by showing people that [staying with the calf] is not what [cows] were meant to do, I guess. They've gotten aware, they know that that calf will be taken care of after we take it, and they just want to go and eat grass and make milk for us" (P1_4).

Students perceived that there was a risk that consumers would shift to dairy alternatives, such as plantbased products, if they are not satisfied with how the industry cares for their animals. They also discussed the possibility of creating milk and meat in laboratories, potentially making farming obsolete: "So, we can make lab milk, and if we say it's humane, no animals were hurt in this situation, people will flock to it" (P3_4). However, some students argued: "I think there will still be a need for cows" (P3_3) and "Not everyone is going to want lab milk" (P3_7).

Whereas there was concern that it would be difficult to get the public to care about information provided ["I don't know that we know of a way to do that without boring people" (P2_4)], other students believed, "But as a whole, I think people really do want to learn" (P5_8) and that the public is "slowly starting to want to go back to understanding something about [farming], which is why there's even a growing target on our backs" (P4_6). Overall, students highlighted the value of focusing on youth "because by the time they're 20-some years old, it's a lot harder to change someone's mind" (P2_1). Students also believed social media would play an increasingly important role, stating that "we're going to have to force education through social media platforms" (P6_5).

According to the students, an important method of public education and gaining public trust was opening up farms ["How will people learn about what we do and about the industry if we just shut it off? It looks shady" (P3_7)]. This could include giving public access to videos recorded by farmers on farms, inviting the public to tour the farms, and hosting live streams online. One student suggested that farms could recruit volunteers to care for the calves, which would expose the public to dairy farming and lighten the burden of the farm workers. Some students also saw a risk with being transparent "because sometimes things can be 
taken out of context" (P3_1), which would lead to bad publicity, but overall agreed that "consumers are definitely going to demand [transparency]" (P1_6).

\section{Support and Joint Effort to Align Dairy Industry with Public Expectations}

Students acknowledged that dairy farmers were responsible for being transparent and for being conscientious in their practices ["Well, it only takes a couple bad farmers to make the whole industry look bad" (P2_2)]. Some students highlighted that "it's all about accountability. So, whether you're coming from the milk quality aspect, or the animal handling aspect, holding those farms accountable for what they're producing and what image they're producing" (P5_6) and that there should be "more scrutinizing of dairy employees and farmers" (P1_4). However, students also realized that there were limitations to what was feasible for farmers: "because [farmers] don't have even enough employees [...] to even get to a point where [they] could be seen in a better light" (P5_4). It was highlighted that farmers have a responsibility to be diligent in the hiring process, training, and supervision of employees "because ultimately, they're the ones that the farmers are counting on" (P1_2).

Students emphasized the role of agricultural communicators to bridge the gap between the dairy industry and the public, being responsible for citizen education ["We need to get our ag communicators as advocates and make them good at it" (P6_5)]. The veterinarian was seen as a relevant supporting figure, for example by ensuring animal care or by speaking to members of the public who were touring the farms. Further, research into animal welfare was regarded as important, e.g., by investigating the consequences of management practices such as group-housing calves. It was highlighted that university farms can be used to demonstrate specific practices, such as cow brushes ["I think that'll make farmers see that these things will work and that they can better the farm" (P1_4)]. Other students suggested researching public views ("I think if we do more surveys asking consumers what exactly that they want, it gets them to think about what they actually perceive as wrong with the industry that we can directly assess and fix." (P2_5). However, according to one student (P6_3), "one could argue that the industry is a little disconnected from academia." Similarly, other students highlighted that a united effort was necessary and P1_4 believed that the topic of animal care "is definitely something we need to get together and talk about to ensure that we're all on the same page." Another student (P6_5) highlighted that stakeholders should make an effort to communicate and understand information, even if not directly related to their immediate role in the dairy industry and followed by stating, "And so, our communicators need to get together and talk to our farmers, our farmers need to talk our policy makers, our policy makers need to talk to our public. It all needs to be very transparent through every single form of career, I guess you could say, rather than keeping things individualized."

Students believed that farmers "want their cows to be healthy and happy [...]. It's just, I'm not sure if they're going to be able to financially support these ways themselves without assistance" (P1_1) and that (government) subsidies might be necessary to support implementation of "must-haves." They argued that dairy operations need to be economically viable and that farmers make decisions based on costs. Referring to cow brushes, one student doubted that farmers would notice an immediate economic return and they "would not see it as being worth the money and effort" (P1_4). In terms of public expectations, P1_2 summarized: "I feel like [lay members of the public] have a lot of ideas that they want implemented in dairies and things like that, but they don't understand how much it's going to cost."

In addition, students suggested that farmers should be financially rewarded when meeting certain standards; for example, in terms of milk quality or environmental stewardship, or that "there should also be repercussions for people who don't meet these standards" (P6_5). Students tied financial rewards and penalties to the existence of legislation that provides guidance and standards to be met. Overall, they believed that there should be mandatory welfare standards ["I think things need to be regulated. That's why we've moved so far in the world that we have." (P2_5)] and highlighted that consistent, industry-driven guidelines would help unify the industry. Further, students believed that mandatory standards are likely to "improve the image of the dairy industry" (P1_1) and dairy products can be marketed accordingly. One student claimed: "So, even though the consumer won't know the policies behind it, as long as the label is there saying it is certified, they'll buy it" (P3_1). However, another student (P2_1) cautioned that the dairy industry should not only be concerned with their image but also implement standards for the sake of the animals: "Why would we do it if the public doesn't even see it? But in the aspect of just animal welfare, we're doing it for the animal, you know? [...] we're supposed to be doing it for [the animals]."

\section{DISCUSSION}

Students mentioned a wide variety of "must-haves" that the dairy industry should meet in the next 20 
yr. However, they did not always clearly distinguish between management practices they believed were necessary for the sake of the animals versus measures taken to meet public expectations. This lack of clarity demonstrates the complexity of the question - namely projecting out what the "must-haves" would be in 2 decades - and challenges associated with defining animal welfare (Fraser et al., 1997). The students appeared to struggle with establishing a threshold of when animal welfare measures are "good enough" and deciding which stakeholder values to place emphasis on when considering welfare issues. Ventura et al. (2015) argued that while stakeholders within the dairy industry may believe that industry practices correspond to a high level of animal care, stakeholder groups external to the dairy industry may regard the same practices as insufficient or inappropriate.

In this study, students raised many examples that reflected the multidimensionality of animal welfare. Although some studies highlighted the focus of dairy industry stakeholders on biological functioning ( $\mathrm{Te}$ Velde et al., 2002; Verbeke, 2009; Cardoso et al., 2019), others argue that this reduction to a unidimensional viewpoint is unfounded and that at least some industry stakeholders have more inclusive conceptions of animal welfare (Spooner et al., 2012; Ventura et al., 2015). The students in this study provided some evidence that they have received mixed messages or that their own critical thinking is in conflict with the messages they received. Similarly, to Armitage-Chan (2020), we believe there is a need to include professional reasoning training (incorporating ethics and critical thinking) in the undergraduate curriculum of students preparing to work in the livestock sector. There is much to gain by contextualizing professional reasoning when current agricultural practices are discussed (Matthew et al., 2010) and providing students the opportunity to debate issues from different angles instead of focusing on either the physiological observations or animal welfare and behavior outcomes. This training would provide students the confidence to critically evaluate current standards and practices, both on the national and individual farm level. As such, they will be able to be independent advisors rather than, by default, aligning their views with perspectives of other stakeholders in the industry. Cardoso et al. (2019) reported that the values of agricultural advisors were often misaligned with the views of lay members of the public but were similar to the values of their primary client: the farmer. However, advisors may be of more long-term use to the industry if they are able to navigate divergent views and help farmers achieve more socially sustainable practices (Meijboom and Meijboom, 2018; Cardoso et al., 2019).
Similarly, Wals and Corcoran (2006) argued that higher education should enable students to integrate, reflect, and confront different ways of how people look at the world. This transformative learning will help students to be able to critically assess and adapt their own worldviews as well as cope with diverging stakeholder values, interests, and reality constructions (Sipos et al., 2008; Howlett et al., 2016).

The journey to sustainable food systems is a compilation of wicked problems, characterized by their complexity, ever-changing contexts, and lack of simple solutions (Kreuter et al., 2004; Hamm, 2009). Over the last decades many challenges within and outside the agricultural context that were once thought to be state-of-the-art are now practices that have been abandoned. This also reflects the possibility of improving the industry despite having goals that many previously considered to be unachievable. According to Stedman and Brown (2020), critical thinking is a requirement to solve today's complex problems. However, to enable students to become capable problem-solvers, sufficient faculty support is necessary to better facilitate the teaching of critical thinking skills (Stedman and Brown, 2020). Armitage-Chan and Maddison (2019) suggested that the lack of a systematic approach in teaching professional reasoning to veterinary students contributes to students' perception that these skills are elusive and removed from practice, and they lacked confidence in being able to acquire these skills. Further, approaches to resolving professional dilemmas and professional reasoning strategies have been poorly articulated by faculty members, perhaps because they themselves have received insufficient formal education in this area (Stern and Papadakis, 2006; Hawick et al., 2017). For veterinary curricula, Armitage-Chan (2020) presents a framework of professional reasoning that helps highlight how subjects such as animal welfare, the human-animal-bond, and professional responsibilities integrate into the decision-making process of veterinary professionals.

While some students realized that communication with the public should be open and nondefensive, and that agricultural representatives should accept the responsibility of being part of that conversation, others took the opposite stance and dismissed specific public expectations as unfeasible. Creating platforms that allow diverse industry stakeholders including the public to openly discuss contentious issues fosters engagement and can help the industry to ensure public trust and social sustainability (Ventura et al., 2013). In the same vein, an honest attempt to understand why members of the public consider specific welfare aspects important is substantially different from just trying to please lay 
members of the public who are perceived to lack agricultural knowledge; the latter mindset still portrays a lack of fully trying to acknowledge the validity of their views. Although the students recognized that public concerns have to be considered and attempts should be made to find compromises, many still believed that the views of the industry are conclusive, and that provision of additional information will lead to public acceptance of current practices (see Ventura et al., 2016a). This notion is in line with the information deficit model (Miller, 2010; Ko, 2016), which assumes that public skepticism of science and technology stems from a lack of knowledge. However, it is now widely accepted that genuine engagement with members of the public, accounting for ethical, religious, and political beliefs, is preferred over simply providing information to change public attitudes (Boykoff, 2009). In this study, the students believed that separating the calf from the cow was best for the animals, despite the lack of evidence in support of this belief (Beaver et al., 2019; Meagher et al., 2019) and argued that with education, lay members of the public could be convinced that the animals do not care about being separated. In contrast, the public often has ethical concerns about cow-calf separation and oppose this practice for the lack of naturalness and ability of the pair to form a bond (Hötzel et al., 2017).

Focus groups were chosen to collect data because they are suitable for exploring a topic that has not been extensively researched and because of their strength to encourage discussion among participants, hence providing in-depth qualitative data that reflect the diversity in existing opinions (Krueger and Casey, 2009). However, it is not the aim of qualitative research to provide results that are generalizable, in the sense assumed by the positivist, quantitative approach (Carminati, 2018). Instead, the researcher is responsible for providing thick descriptions of the data, allowing others to evaluate whether findings are transferable to other contexts (Lincoln and Guba, 1985). Future research avenues include studying the views of different student cohorts (e.g., veterinary students and students in different countries), and using quantitative methods to assess student perspectives of a larger and more representative sample.

Moderators may have influenced the students' opinions, but this effect was likely minimal, given that the focus group discussion was the first interaction between moderators and students. Further, the review of recordings and transcripts indicated very little involvement of the moderators in the discussion. We conducted all focus groups simultaneously, during the first official hour of instruction of the USDETC; options to collect more data with additional students would have been limited due to logistical constraints. However, after analysis of the 6 transcripts it was apparent that saturation was reached, such that it seemed unlikely that new codes or themes would emerge from additional transcripts (Saunders et al., 2018).

\section{CONCLUSIONS}

Students often failed to distinguish between the "must-haves" that promote animal health and welfare, and changes in animal care practices for the purposes of meeting public expectations. This finding highlights the complexity of the issue and the perceived influence the public has on the future of the dairy industry. As such, students emphasized the importance of accounting for values held by members of the public to ensure continued support of the dairy industry by the public. Although the need for compromises was raised, students believed that educating the public was necessary (and sufficient) to align public expectations with dairy industry practices.

\section{ACKNOWLEDGMENTS}

The authors thank the organizers, in particular Robert Hagevoort (New Mexico State University) and Michael A. Tomaszewski (Texas A\&M University), and the students of the 2019 Consortium for allowing us to undertake this study. Caroline Ritter was supported by a Government of Canada Banting Post-Doctoral Fellowship (Ottawa, ON, Canada). Additional funding for this project was provided by the Hans Sigrist Research Prize (Bern, Switzerland) awarded to Marina von Keyserlingk (Animal Welfare Program, Vancouver, BC, Canada). The authors have not stated any conflicts of interest.

\section{REFERENCES}

Alonso, M. E., J. R. González-Montaña, and J. M. Lomillos. 2020. Consumers' concerns and perceptions of farm animal welfare. Animals (Basel) 10:385. https://doi.org/10.3390/ani10030385.

Armitage-Chan, E. 2020. Best practice in supporting professional identity formation: Use of a professional reasoning framework. J. Vet. Med. Educ. 47:125-136. https://doi.org/10.3138/jvme.0218-019r.

Armitage-Chan, E., and J. Maddison. 2019. The influences of curriculum area and student background on mindset to learning in the veterinary curriculum: A pilot study. Vet. Med. Sci. 5:470-482. https://doi.org/10.1002/vms3.174.

Beaver, A., R. K. Meagher, M A G. von Keyserlingk, and D. M. Weary. 2019. Invited review: A systematic review of the effects of early separation on dairy cow and calf health. J. Dairy Sci. 102:5784-5810. https://doi.org/10.3168/jds.2018-15603.

Benard, M., and T. de Cock Buning. 2013. Exploring the potential of Dutch pig farmers and urban-citizens to learn through frame reflection. J. Agric. Environ. Ethics 26:1015-1036. https://doi.org/ 10.1007/s10806-013-9438-y. 
Bennett, R. M., J. Anderson, and R. J. P. Blaney. 2002. Moral intensity and willingness to pay concerning farm animal welfare issues and the implications for agricultural policy. J. Agric. Environ. Ethics 15:187-202. https://doi.org/10.1023/A:1015036617385.

Boogaard, B. K., B. B. Bock, S. J. Oosting, J. S. C. Wiskerke, and A. J. van der Zijpp. 2011. Social acceptance of dairy farming: The ambivalence between the two faces of modernity. J. Agric. Environ. Ethics 24:259-282. https://doi.org/10.1007/s10806-010 -9256-4.

Boykoff, M. T. 2009. What have future generations done for me lately?: Climate change causes, consequences, and challenges in the new millennium. Glob. Environ. Polit. 9:123-128. https://doi.org/ 10.1162/glep.2009.9.2.123.

Cambridge Business Dictionary. 2011. The general public. Cambridge University Press. Accessed Feb. 18, 2021. https://dictionary .cambridge.org/dictionary/english/general-public.

Cardoso, C. S., M. G. von Keyserlingk, and M. J. Hötzel. 2019. Views of dairy farmers, agricultural advisors, and lay citizens on the ideal dairy farm. J. Dairy Sci. 102:1811-1821. https://doi.org/10.3168/ jds.2018-14688.

Carminati, L. 2018. Generalizability in qualitative research: A tale of two traditions. Qual. Health Res. 28:2094-2101. https://doi.org/ $10.1177 / 1049732318788379$.

Cidell, J. 2010. Content clouds as exploratory qualitative data analysis. Area 42:514-523. https://doi.org/10.1111/j.1475-4762.2010 .00952.x.

Clark, B., G. Stewart, L. Panzone, I. Kyriazakis, and L. Frewer. 2016. A systematic review of public attitudes, perceptions and behaviours towards production diseases associated with farm animal welfare. J. Agric. Environ. Ethics 29:455-478. https://doi.org/10 $.1007 / \mathrm{s} 10806-016-9615-\mathrm{x}$

Cohen, D. J., and B. F. Crabtree. 2008. Evaluative criteria for qualitative research in health care: Controversies and recommendations. Ann. Fam. Med. 6:331-339. https://doi.org/10.1370/afm.818.

Corlett, S., and S. Mavin. 2018. Reflexivity and researcher positionality. The SAGE Handbook of Qualitative Business and Management Research Methods; Vol. 1: History and Traditions. SAGE Publications.

Cornish, A., D. Raubenheimer, and P. McGreevy. 2016. What we know about the public's level of concern for farm animal welfare in food production in developed countries. Animals (Basel) 6:74. https://doi.org/10.3390/ani6110074.

de Rooij, S. J. G., C. C. de Lauwere, and J. D. Ploeg. 2010. Entrapped in group solidarity? Animal welfare, the ethical positions of farmers and the difficult search for alternatives. J. Environ. Policy Plann. 12:341-361. https://doi.org/10.1080/1523908X.2010 .528882 .

DeCuir-Gunby, J. T., P. L. Marshall, and A. W. McCulloch. 2011. Developing and using a codebook for the analysis of interview data: An example from a professional development research project. Field Methods 23:136-155. https://doi.org/10.1177/1525822X10388468.

Denzin, N. K., and Y. S. Lincoln. 1994. Handbook of Qualitative Research. SAGE Publications.

Fletcher, A. J. 2017. Applying critical realism in qualitative research: Methodology meets method. Int. J. Soc. Res. Methodol. 20:181194. https://doi.org/10.1080/13645579.2016.1144401.

Fraser, D., D. M. Weary, E. A. Pajor, and B. N. Milligan. 1997. A scientific conception of animal welfare that reflects ethical concerns. Anim. Welf. 6:187-205.

Hamm, M. W. 2009. Principles for framing a healthy food system. J. Hunger Environ. Nutr. 4:241-250. https://doi.org/10.1080/ 19320240903321219.

Hawick, L., J. Cleland, and S. Kitto. 2017. Sending messages: How faculty influence professionalism teaching and learning. Med. Teach. 39:987-994. https://doi.org/10.1080/0142159X.2017.1337271.

Hennink, M., I. Hutter, and A. Bailey. 2011. Qualitative Research Methods. SAGE Publications.

Hötzel, M. J., C. S. Cardoso, A. Roslindo, and M. A. G. von Keyserlingk. 2017. Citizens' views on the practices of zero-grazing and cow-calf separation in the dairy industry: Does providing informa- tion increase acceptability? J. Dairy Sci. 100:4150-4160. https:// doi.org/10.3168/jds.2016-11933.

Howlett, C., J. Ferreira, and J. Blomfield. 2016. Teaching sustainable development in higher education. Int. J. Sustain. High. Educ. 17:305-321. https://doi.org/10.1108/IJSHE-07-2014-0102.

Isenhour, C. 2011. Can consumer demand deliver sustainable food? Recent research in sustainable consumption policy and practice. Environ. Soc. 2:5-28.

Ko, H. 2016. In science communication, why does the idea of a public deficit always return? How do the shifting information flows in healthcare affect the deficit model of science communication? Public Underst. Sci. 25:427-432. https://doi.org/10.1177/ 0963662516629746.

Kreuter, M. W., C. De Rosa, E. H. Howze, and G. T. Baldwin. 2004. Understanding wicked problems: A key to advancing environmental health promotion. Health Educ. Behav. 31:441-454. https://doi .org/10.1177/1090198104265597.

Krueger, R. A., and M. A. Casey. 2009. Focus Groups: A Practical Guide for Applied Research. 4th ed. ed. SAGE Publications.

Lincoln, Y., and E. G. Guba. 1985. Naturalistic Inquiry. SAGE Publications.

Marshall, C., and G. B. Rossman. 2006. Designing Qualitative Research. 4th ed. SAGE Publications.

Mason-Bish, H. 2019. The elite delusion: Reflexivity, identity and positionality in qualitative research. Qual. Res. 19:263-276.

Matthew, S. M., R. M. Taylor, and R. A. Ellis. 2010. Students' experiences of clinic-based learning during a final year veterinary internship programme. High. Educ. Res. Dev. 29:389-404. https://doi .org/10.1080/07294361003717903.

Meagher, R. K., A. Beaver, D. M. Weary, and M A G. von Keyserlingk. 2019. Invited review: A systematic review of the effects of prolonged cow-calf contact on behavior, welfare, and productivity. J. Dairy Sci. 102:5765-5783. https://doi.org/10.3168/jds.2018 $-16021$.

Meijboom, F., and F. Meijboom. 2018. More than just a vet? Professional integrity as an answer to the ethical challenges facing veterinarians in animal food production. Food Ethics 1:209-220. https:/ /doi.org/10.1007/s41055-017-0019-z.

Miles, M. B., A. M. Huberman, and J. Saldana. 2014. Qualitative Data Analysis: A Methods Sourcebook. 3rd ed. SAGE Publications.

Miller, S. 2010. Deficit model. Pages 208-209 in Encyclopedia of Science and Technology Communication. S. Priest, ed. SAGE Publications.

Nowell, L. S., J. M. Norris, D. E. White, and N. J. Moules. 2017. Thematic analysis: Striving to meet the trustworthiness criteria. Int. J. Qual. Methods 16:1-13. https://doi.org/10.1177/ 1609406917733847.

Ritter, C., K. E. Mills, D. M. Weary, and M. A. G. von Keyserlingk. 2020. Perspectives of western Canadian dairy farmers on the future of farming. J. Dairy Sci. 103:10273-10282. https://doi.org/10 .3168/jds.2020-18430.

Roberts, K., A. Dowell, and J. Nie. 2019. Attempting rigour and replicability in thematic analysis of qualitative research data; a case study of codebook development. BMC Med. Res. Methodol. 19:66. https://doi.org/10.1186/s12874-019-0707-y.

Román, S., L. M. Sánchez-Siles, and M. Siegrist. 2017. The importance of food naturalness for consumers: Results of a systematic review. Trends Food Sci. Technol. 67:44-57. https://doi.org/10.1016/j.tifs .2017.06.010.

Saunders, B., J. Sim, T. Kingstone, S. Baker, J. Waterfield, B. Bartlam, H. Burroughs, and C. Jinks. 2018. Saturation in qualitative research: Exploring its conceptualization and operationalization. Qual. Quant. 52:1893-1907. https://doi.org/10.1007/s11135 $-017-0574-8$

Schröder, M. J. A., and M. G. McEachern. 2004. Consumer value conflicts surrounding ethical food purchase decisions: A focus on animal welfare. Int. J. Consum. Stud. 28:168-177. https://doi.org/ 10.1111/j.1470-6431.2003.00357.x.

Sipos, Y., B. Battisti, and K. Grimm. 2008. Achieving transformative sustainability learning: Engaging head, hands and heart 
Int. J. Sustain. High. Educ. 9:68-86. https://doi.org/10.1108/ 14676370810842193.

Spooner, J. M., C. A. Schuppli, and D. Fraser. 2012. Attitudes of Canadian beef producers toward animal welfare. Anim. Welf. 21:273283. https://doi.org/10.7120/09627286.21.2.273.

Stedman, N., and A. Brown. 2020. Critical thinking perspectives of undergraduate students: How they think about climate change impacts on global food security and hunger. Adv. Agri. Dev. 1:14-24. https://doi.org/10.37433/aad.v1i1.29.

Stern, D. T., and M. Papadakis. 2006. The developing physician - Becoming a professional. N. Engl. J. Med. 355:1794-1799. https://doi .org/10.1056/NEJMra054783.

Te Velde, H., N. Aarts, and C. van Woerkum. 2002. Dealing with ambivalence: Farmers' and consumers' perceptions of animal welfare in livestock breeding. J. Agric. Environ. Ethics 15:203-219. https: //doi.org/10.1023/A:1015012403331.

Ventura, B. A., M. A. G. von Keyserlingk, C. A. Schuppli, and D. M. Weary. 2013. Views on contentious practices in dairy farming: The case of early cow-calf separation. J. Dairy Sci. 96:6105-6116. https: //doi.org/10.3168/jds.2012-6040.

Ventura, B. A., M. A. G. von Keyserlingk, and D. M. Weary. 2015. Animal welfare concerns and values of stakeholders within the dairy industry. J. Agric. Environ. Ethics 28:109-126. https://doi.org/10 $.1007 / \mathrm{s} 10806-014-9523-\mathrm{x}$
Ventura, B. A., M. A. G. von Keyserlingk, H. Wittman, and D. M. Weary. 2016a. What difference does a visit make? Changes in animal welfare perceptions after interested citizens tour a dairy farm. PLoS One 11:e0154733. https://doi.org/10.1371/journal.pone .0154733 .

Ventura, B. A., D. M. Weary, A. S. Giovanetti, and M. A. G. von Keyserlingk. 2016b. Veterinary perspectives on cattle welfare challenges and solutions. Livest. Sci. 193:95-102. https://doi.org/10 .1016/j.livsci.2016.10.004

Verbeke, W. 2009. Stakeholder, citizen and consumer interests in farm animal welfare. Anim. Welf. 18:325-333.

Wals, A., and B. P. Corcoran. 2006. Sustainability as an outcome of transformative learning in education for sustainable development in action. Technical Paper No. 3:103-110. UNESCO.

\section{ORCIDS}

Caroline Ritter @ https://orcid.org/0000-0001-7349-5241

Elizabeth R. Russell ๑ https://orcid.org/0000-0001-9202-439X

Daniel M. Weary (ํ) https://orcid.org/0000-0002-0917-3982

Marina A. G. von Keyserlingk () https://orcid.org/0000-0002-1427 $-3152$ 


\section{APPENDIX}

Table A1. Codebook created from 6 focus groups conducted with undergraduate animal and dairy students about the future of dairy farms and public expectations around care of dairy cattle

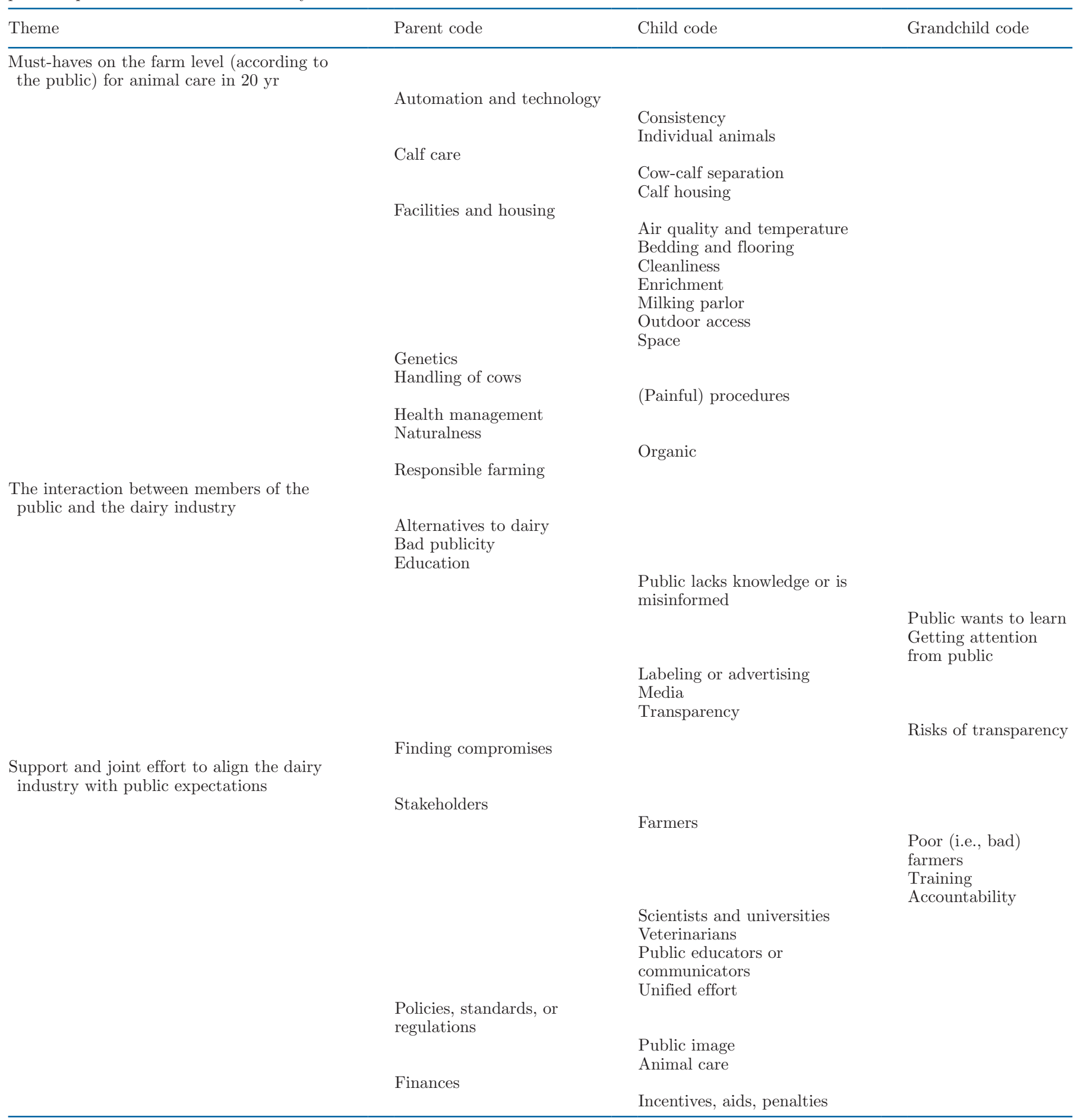

